\title{
An Algebraic Turbulence Model for Three-Dimensional Viscous Flows
}

R.V. Chima

National Aeronautics and Space Administration

Lewis Research Center

Cleveland, Ohio

P.W. Giel

Sverdrup Technology, Inc.

Lewis Research Center Group

Brook Park, Ohio

and

R.J. Boyle

National Aeronautics and Space Administration

Lewis Research Center

Cleveland, Ohio

Prepared for the

31st Aerospace Sciences Meeting and Exhibit

sponsored by the American Institute of Aeronautics and Astronautics

Reno, Nevada, January 11-14, 1993 



\title{
AN ALGEBRAIC TURBULENCE MODEL FOR THREE-DIMENSIONAL VISCOUS FLOWS
}

\author{
R. V. Chima, ${ }^{1 *}$ P. W. Giel, ${ }^{2 *}$ and R. J. Boyle ${ }^{1 *}$ \\ ${ }^{1}$ NASA Lewis Research Center, Cleveland, Ohio \\ ${ }^{2}$ Sverdrup Technology, Inc. (Lewis Research Center Group), Brook Park, Ohio
}

\begin{abstract}
An algebraic turbulence model is proposed for use with three-dimensional Navier-Stokes analyses. It incorporates features of both the Baldwin-Lomax and Cebeci-Smith models. The Baldwin-Lomax model uses the maximum of a function $f(y)$ to determine length and velocity scales. An analysis of the Baldwin-Lomax model shows that $f(y)$ can have a spurious maximum close to the wall, causing numerical problems and nonphysical results. The proposed model uses integral relations to determine $\delta^{*} u_{e}$ and $\delta$ used in the CebeciSmith model. It eliminates a constant in the BaldwinLomax model and determines the two remaining constants by comparison to the Cebeci-Smith formulation. Pressure gradient effects, a new wake model, and the implementation of these features in a threedimensional Navier-Stokes code are also described. Result are shown for a flat plate boundary layer, an annular turbine cascade, and endwall heat transfer in a linear turbine cascade. The heat transfer results agree well with experimental data which shows large variations in endwall Stanton number contours with Reynolds number.
\end{abstract}

\section{INTRODUCTION}

The Baldwin-Lomax turbulence model (BLM) was developed in 1981 [1] as a simple algebraic turbulence model for use with Navier-Stokes codes. The model is based on the widely-used Cebeci-Smith boundary layer model (CSM, [2]), with modifications made to avoid the need to search for the edge of the boundary layer.

Since its development, the BLM has become one of the most widely used turbulence models in computational fluid dynamics. NASA's RECON library database lists 287 references written since the original publication [1] that included the names Baldwin or Lomax in their abstracts. Most references indicated that the model was successful. Some noted physical details

\footnotetext{
* Member AIAA

Copyright $\odot 1993$ by AIAA, Inc. No copyright is asserted in the United States under Title 17, U.S. Code. The U.S. Government has a royalty-free license to exercise all rights under the copyright claimed herein for Governmental purposes. All other rights are reserved by the copyright owner.
}

missing from the model, e.g. pressure gradient effects [3] which are discussed later. A few noted disagreement between the constants in the BLM and the CSM $[4,5,6]$. Finally, several references noted numerical problems with the model, usually a failure to find the correct outer length scale. This problem is covered in detail here and an alternative model is proposed.

The present work began as an attempt to calculate endwall heat transfer in a linear turbine cascade studied experimentally by Boyle and Russell [7], who found two distinctly different heat transfer patterns at low and high Reynolds numbers. Calculations of the cascade were made with the three-dimensional NavierStokes code described in $[8,9]$. Initial calculations using the BLM looked promising but showed isolated regions of unrealistically high or low heat transfer. The problem was traced to multiple peaks in the BaldwinLomax function $f(y)$ used to determine a turbulent length scale, which led to incorrect estimates of the turbulent viscosity and boundary layer thickness.

An analysis of the BLM was performed, similar to $[4,5,6]$. Like the previous work, it was found that the constants used in the BLM do not give agreement with the CSM. Unlike the previous work, it was also shown that $f(y)$ can have a spurious maxima at the edge of the viscous sublayer, especially in favorable pressure gradients and at low Reynolds numbers.

A new turbulence model was developed that avoids searching for $f_{\max }$. It uses the relation $\int_{0}^{\infty} f d y=\delta^{*} u_{e}$ (shown independently in [10]) directly in the CebeciSmith model and correlates $\delta$ with the centroid of the $f(y)$ curve. The model avoids one of the constants used in the BLM, and determines the two remaining constants by comparison with the CSM. It also includes pressure gradient effects and a new wake model.

Calculations made of the endwall heat transfer problem using the new model show the change in heat transfer pattern with Reynolds number and agree fairly well with the experiment.

\section{NUMERICAL METHOD}

The code described by Chima in $[8,9]$ was used in the present work, and is described below briefly. The code, referred to as rvc3d (Rotor Viscous Code 3-D) is a Navier-Stokes code for analysis of steady flows in 
turbomachinery blade passages. The governing equations are formulated in Cartesian coordinates including rotation about the $x$-axis, and transformed to general body-fitted coordinates. The Navier-Stokes equations are discretized using second-order central finite differences. The thin-layer approximation is used to neglect streamwise viscous terms, but all blade-to-blade and hub-to-tip viscous terms are retained.

An explicit four-stage Runge-Kutta time-marching scheme is used to solve the flow equations. Fourthdifference artificial dissipation terms are added. A spatially varying time step and implicit residual smoothing are used for convergence acceleration.

C-type grids are generated in a blade-to-blade plane using a version of Steger and Sorenson's GRAPE code. The $\mathrm{C}$-grids give good resolution of the leading edge and the wake. Grids are stacked spanwise using a hyperbolic tangent stretching function.

Boundary conditions for the cascade heat transfer problem were as follows: On the blade and endwall the no-slip condition was imposed on the velocity components, the wall pressure was found from the normal momentum equation, and the wall temperature was set to $1.2 \times T_{0 \text { in }}$ to cause heat transfer from the walls. The flow was assumed to be periodic blade-to-blade and symmetric about the mid-span. At the exit boundary $p$ was specified and $\rho, \rho u, \rho v$, and $\rho w$ were extrapolated from the interior.

- At the inlet boundary, $P_{0}, T_{0}, v$ and $w$ profiles were specified. The velocity profiles were computed using a turbulent law-of-the-wall profile matched to the measured inlet boundary layer thickness and freestream velocity. $P_{0}$ was computed from the velocity profile and the measured static pressure. $T_{0}$ was computed using a thermal law-of-the-wall profile chosen to match the measured inlet Stanton number. Stanton numbers within the blade row were insensitive to the inlet value. A Riemann invariant $R^{-}$based on $u$ is extrapolated from an interior grid point to the inlet. A correction to $R^{-}$is made for non-isentropic flow due to bound. ary layer dissipation and endwall heat transfer, using a technique to be described in a later paper. $R^{-}$and $T_{0}$ are then solved for $u$ and $c$ at the inlet.

\section{CEBECI-SMITH MODEL}

In Navier-Stokes analyses the effective viscosity and effective thermal conductivity are taken to be the sum of laminar and turbulent components, i.e.,

$$
\begin{aligned}
\mu_{e f f} & =\mu_{\text {lam }}+\mu_{t u r b} \\
\frac{\mu_{\text {lam }}}{\mu_{\text {ref }}} & =\left(\frac{T}{T_{\text {ref }}}\right)^{n} \\
k_{\text {eff }} & =C_{p}\left(\frac{\mu_{\text {lam }}}{\mathbf{P r}_{\mathbf{r}}}+\frac{\mu_{\text {turb }}}{\mathbf{P r}_{t}}\right)
\end{aligned}
$$

where $\operatorname{Pr}_{t}=0.9$ is the turbulent Prandtl number and $n=0.667$.
The Cebeci-Smith model [2] is a two-layer algebraic model for the turbulent viscosity:

$$
\mu_{t u r b}=\left\{\begin{array}{l}
\mu_{i} \text { for } y \leq y_{c} \\
\mu_{o} \text { for } y>y_{c}
\end{array}\right.
$$

where $y_{c}$ is the first point at which $\mu_{i}>\mu_{0}$.

A Prandtl-van Driest formulation is used for the inner layer:

$$
\begin{aligned}
\mu_{i} & =\rho l^{2}\left|\frac{\partial u}{\partial y}\right| \\
l & =\kappa y D \\
D & =1-\exp \left(-y^{+} / A^{+}\right) \\
y^{+} & =y \frac{u^{*}}{\nu} \text { and } u^{*}=\sqrt{\frac{\tau_{\text {wall }}}{\rho}}
\end{aligned}
$$

Here $\rho$ is the density, $\kappa=0.4$ is the von Karman constant, $D$ is the van Driest damping function with $A^{+}=26$, and $|\partial u / \partial y|$ is the absolute value of the velocity gradient.

A Clauser formulation is used for the outer layer:

$$
\mu_{o}=K \rho \gamma \delta^{*} u_{e}
$$

where $\delta^{*}$ is the displacement thickness and $u_{e}$ is the edge velocity. The Klebanoff intermittency function is given by:

$$
\gamma=\left[1+5.5\left(\frac{y}{\delta}\right)^{6}\right]^{-1}
$$

\section{BALDWIN-LOMAX MODEL}

The Baldwin-Lomax Model [1] is derived from the Cebeci-Smith model described above. In the BLM the inner formulation is identical to (3) except that the magnitude of the vorticity $|\omega|$ replaces $|\partial u / \partial y|$.

The BLM replaces the outer formulation of the CSM with:

$$
\mu_{o}=K \rho \gamma C_{c p} \min \left\{\begin{array}{l}
y_{\max } f_{\max } \\
C_{w k} y_{\max } u_{d i f f}^{2} / f_{\max }
\end{array}\right.
$$

where $K=.0168$ is the Clauser constant and $C_{c p}=1.6$ is an additional constant.

The product $y_{\max } f_{\max }$ replaces $\delta^{*} u_{e}$ in the CSM The function $f(y)$ is defined by:

$$
\begin{aligned}
f(y) & =y|\omega| D \\
f_{\max } & =\max (f(y)) \\
y_{\max } & =y \text { at } f_{\max }
\end{aligned}
$$

Later it is shown that $y_{\max }$ usually occurs at a fixed fraction of $\delta$, but that in certain cases $y_{\max }$ occurs at the edge of the viscous sublayer, and the BLM fails.

In the intermittency function (5) the BLM replaces $y / \delta$ with $C_{K l e b} y / y_{\max }$, where $C_{K l e b}=0.3$. In wakes $D$ is set to 1 and the lower option in (6) is used (it may also be active at separation.) $C_{w k}$ was originally 


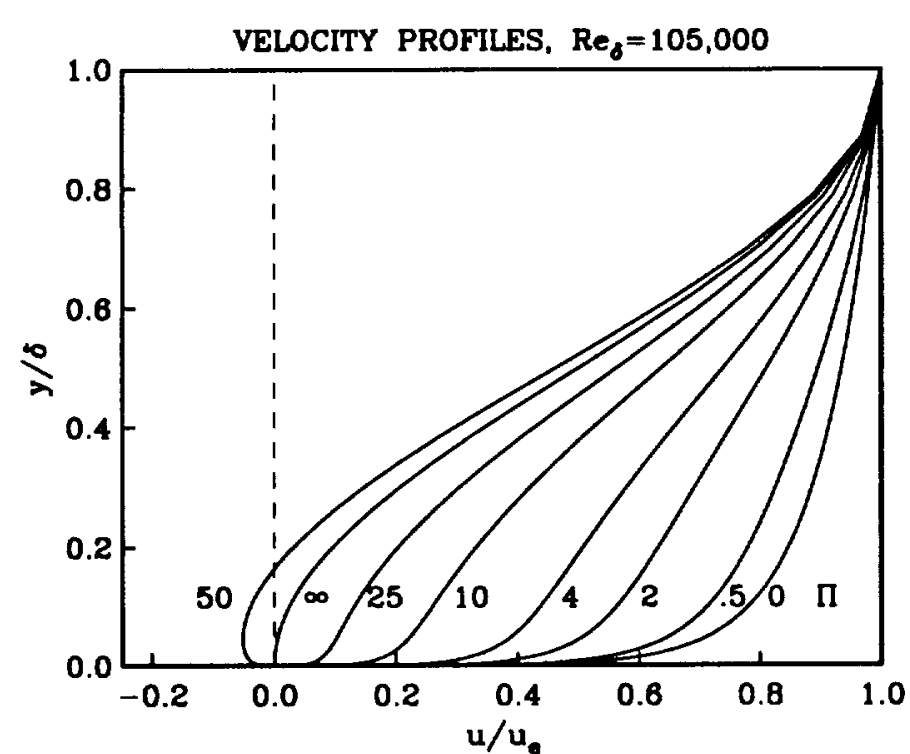

Figure 1.- Turbulent velocity profiles for a range of pressure gradient parameters II.

reported as 0.25 but is generally taken to be 1.0 . The term $u_{\text {diff }}=\left|V_{\max }\right|-\left|V_{\min }\right|$ is the difference between the maximum and minimum total velocities in a profile. Recent papers have replaced $V_{\max }$ with $V\left(y_{\max }\right)$.

\section{BALDWIN-LOMAX MODEL ANALYSIS}

Several authors have analyzed the BLM to show why the function $f(y)$ is used, and to adjust $C_{K l e b}$ and $C_{c p}$ for agreement with the CSM $[4,5,6]$. The analysis of [5] is given briefly below for reference. It is then extended to show when the BLM might fail, and finally used to develop a new model based on the original CSM.

Cole's turbulent velocity profile is used in the analysis of the BLM. In the viscous sublayer:

$$
u^{+}=y^{+}
$$

and in the wall-wake region:

$$
\begin{aligned}
& \frac{u}{u_{e}}= \frac{u^{*}}{u_{e}}\left[\frac{1}{\kappa} \ln \left(\operatorname{Re}_{\delta}\left|\frac{u^{*}}{u_{e}}\right| \frac{y}{\delta}\right)+B\right] \\
&+\frac{\Pi}{\kappa}\left|\frac{u^{*}}{u_{e}}\right|\left(1-\cos \left(\frac{\pi y}{\delta}\right)\right)
\end{aligned}
$$

where $B=5.5$, and II is a pressure gradient parameter given by:

$$
\Pi=0.9(\beta+.5)^{75}, \quad \beta=\frac{\delta^{*}}{\tau_{w a l l}} \frac{d p_{e}}{d x}
$$

An infinitely favorable pressure gradient has $\Pi=0$, an equilibrium gradient has $\Pi=0.5$, and an infinitely adverse gradient has $\Pi=\infty$. For a specified value of II, (9) may be evaluated at $u=u_{e}$ and $y=\delta$, and solved for the friction velocity $u^{*}$. The equation has two roots with opposite signs, giving separated profiles

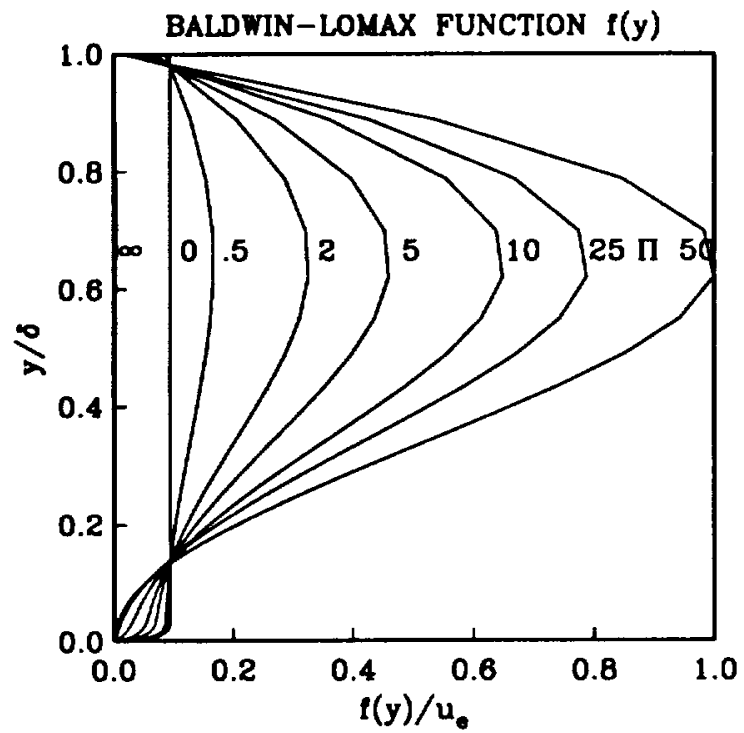

Figure 2.-Profiles of the Baldwin-Lomax function $f(y)$ corresponding to figure 1 .

when $u^{*}$ is negative. Figure 1 shows several turbulent velocity profiles over a range of $\Pi$ for $\mathrm{Re}_{\delta}=105,000$, the value used in [5].

The Baldwin-Lomax function $f(y)=y|\omega| D$ can be computed from (9) by replacing $|\omega|$ with $|d u / d y|$ and neglecting $\mathrm{D}$, which is meant to damp spurious maxima in the viscous sublayer $(y / \delta<0.05)$. The resulting expression for $f(y)$ is:

$$
f(y)=y|\omega|=\frac{\left|u^{*}\right|}{\kappa}\left[1+\Pi \frac{\pi y}{\delta} \sin \left(\frac{\pi y}{\delta}\right)\right]
$$

The maximum of $f(y)$ occurs where $\frac{y}{\delta} \sin \left(\frac{\pi y}{\delta}\right)$ is $\max$ imum, which occurs independently of $\Pi$ at

$$
y_{\max }=0.646 \delta
$$

Figure 2 shows profiles of the Baldwin-Lomax function $f(y)$ for the velocity profiles shown in figure 1 .

For an infinitely adverse gradient $(\Pi=\infty) \tau_{w \text { all }}=$ $y^{+}=D=\mu_{o}=0$, which can cause numerical problems. For an adverse gradient (e.g. $\Pi=5$ ) there is a clear maximum in $f(y)$ and the BLM is well-behaved. For an equilibrium layer ( $I=0.5$ ) there is a weak maximum in the outer part of the boundary layer where grids are relatively coarse and small errors in the solution can lead to large errors in $y_{\max }$. For an infinitely favorable gradient (II $=0) f(y)$ is constant in the outer layer and the BLM fails.

The constants $C_{K l e b}$ and $C_{c p}$ are evaluated by comparing the BLM to the CSM. Briefly, $C_{K l e b}$ is evaluated by comparing the intermittency formulations, giving $C_{K l e b}=0.646$. Baldwin and Lomax suggested $C_{K l e b}=0.3$, giving little intermittency. $C_{c p}$ is evaluated by comparing the outer formulations. The displacement thickness $\delta^{*}$ is found by integrating $\left(u_{e}-u\right)$ 
using (9). The result is:

$$
C_{c p}=\frac{1+\Pi}{.646(1+1.8197 \Pi)}
$$

Thus $C_{c p}$ is a strong function of pressure gradient, ranging from $C_{c p}=1.548$ at $\Pi=0$ to $C_{c p}=0.851$ at $\Pi=\infty$. The equilibrium value $C_{c p}=1.216$ at $I I=0.5$ is recommended over Baldwin and Lomax's suggested value of $C_{c p}=1.6$.

\section{SPURIOUS MAXIMA IN $f(y)$}

For the BLM to work properly, $y_{\max }$ must reliably correlate with $\delta$, as in equation (12). Several authors have reported problems with spurious maxima in $f(y)$ very close to the wall, e.g., $[4,10]$. Here it is shown that under some conditions $f(y)$ has a spurious maximum in the viscous sublayer.

The function $f(y)$ given in (11) is based on the wallwake profile(9). The function can also be evaluated in the viscous sublayer using $(8)$, giving:

$$
f_{\text {sub }}^{+}=y^{+}\left|\frac{d u^{+}}{d y^{+}}\right| D=y^{+} D
$$

the maximum of which occurs at the edge of the sublayer.

For simplicity consider an infinitely favorable pressure gradient $(I=0)$. The sublayer and wall-wake profiles meet at $y_{\text {sub }}^{+}=11.635$, where (14) gives $f_{\max }^{+}=$ 4.2. The outer profile (11) gives $f_{\max }^{+}=1 / \kappa=2.5$. Thus for $\Pi=0, f(y)$ has two local maxima, and the largest occurs at the edge of the viscous sublayer, even when the van Driest damping term $D$ is used to suppress the spurious maximum. In reality a buffer layer blends the viscous sublayer and the wall region smoothly, and the spurious maximum is reduced. Similar results are found for certain II $>0$, depending on $\operatorname{Re}_{\delta}$. For example, for a fairly high $\operatorname{Re}_{\delta}=105,000$ (fig. 1 and 2) $f_{\max -s u b}>f_{\max -o u t e r}$ for $I I<0.28$. It can be shown that spurious maxima are most likely in favorable pressure gradients and at low $\mathrm{Re}_{\delta}$.

\section{PROPOSED TURBULENCE MODEL}

The inner formulation is similar to the BLM formulation:

$$
\mu_{i}=\rho l^{2}|\omega|
$$

where $l, D$, and $y^{+}$are as defined in (3) and $\kappa=0.4$.

The friction velocity $u^{*}$ used in (3) is usually defined in terms of the wall shear $\tau_{w a l l}$. Several researchers have modified $u^{*}$ by replacing $\tau_{\text {wall }}=0$ with the local shear in the profile, either to avoid problems at separation [4] where $\tau_{w a l l}=0$, or as an indirect way to allow the boundary layer to respond to pressure gradients [11].

$$
u^{*}=\sqrt{\frac{\tau_{\text {wall }}}{\rho}} \rightarrow \sqrt{\frac{\tau(y)}{\rho}}
$$

In practice $\tau$ is replaced by $\mu|\omega|$. Results using the two formulations are discussed later.

Cebeci's extension of van Driest's damping model [2] is used to allow the boundary layer to relaminarize in response to favorable pressure gradients.

$$
A^{+}=\frac{26}{\sqrt{1+11.8 p^{+}}}, \quad p^{+}=\frac{\nu}{\rho u^{* 3}} \frac{\partial p}{\partial s}
$$

The local pressure gradient is evaluated using:

$$
\frac{\partial p}{\partial s} \approx \frac{\vec{V}_{e}}{\left|\vec{V}_{e}\right|} \cdot \nabla p
$$

The "edge" velocity $\vec{V}_{e}$ is evaluated at a grid line far enough from the wall to indicate the general flow direction.

The outer formulation is given by:

$$
\begin{aligned}
& \mu_{o}=K \rho \gamma \min \left\{\begin{array}{l}
F \\
C_{w k} \bar{y}\left(\left|V_{\max }\right|-\left|V_{\min }\right|\right)
\end{array}\right. \\
& \gamma=\left[1+5.5\left(\frac{C_{K l e b} y}{\bar{y}}\right)^{6}\right]^{-1}
\end{aligned}
$$

where $C_{K l e b}=0.55$ and $C_{w k}=0.825$, as derived below.

The function $\mathrm{F}$ is an integral of the BL function $f(y)$ without the damping term $D$.

$$
F=\int_{0}^{\infty} f(y) d y=\int_{0}^{\infty} y \frac{\partial u}{\partial y} d y=\delta^{*} u_{e}
$$

shown using integration by parts and assuming that $\lim _{y \rightarrow \delta}(\partial u / \partial y)=0$. This relationship was discovered independently by Johnson [10] but was rejected in favor of another scheme based on $f_{\max }$. In practice $\partial u / \partial y$ is replaced with $|\omega|$, which goes to zero at $\delta$, even if $\partial u / \partial y$ does not. The integral scale $F$ provides an unambiguous measure of the product $\delta^{*} u_{e}$ without having to evaluate either term directly. It is used in the outer formulation of the CSM (4), avoiding the constant $C_{c p}$ entirely.

The length scale $\bar{y}$ is the centroid of the $f(y)$ curve, defined by:

$$
\int_{0}^{y j} f(y) d y=\int_{\bar{y}}^{\delta} f(y) d y
$$

Substituting (11) for $f(y)$, the integrals may be evaluated analytically. The result is a transcendental equation for $\bar{y} / \delta$ as a weak function of $\Pi$, which is solved numerically. For $\Pi=0, \bar{y} / \delta=0.5$, which is obvious from figure 2 . For II $=.5, \bar{y} / \delta=.55$, and for $\Pi=\infty, \bar{y} / \delta=.606$. The equilibrium value $\bar{y} / \delta=.55 \equiv C_{K l e b}$ was used in the present work.

The model is implemented by replacing $\partial u / \partial y$ with $|\omega|$ in (20) and integrating numerically. The accumulated integral is stored in an array at each point in the profile. When the integration is complete, $F / 2$ gives 


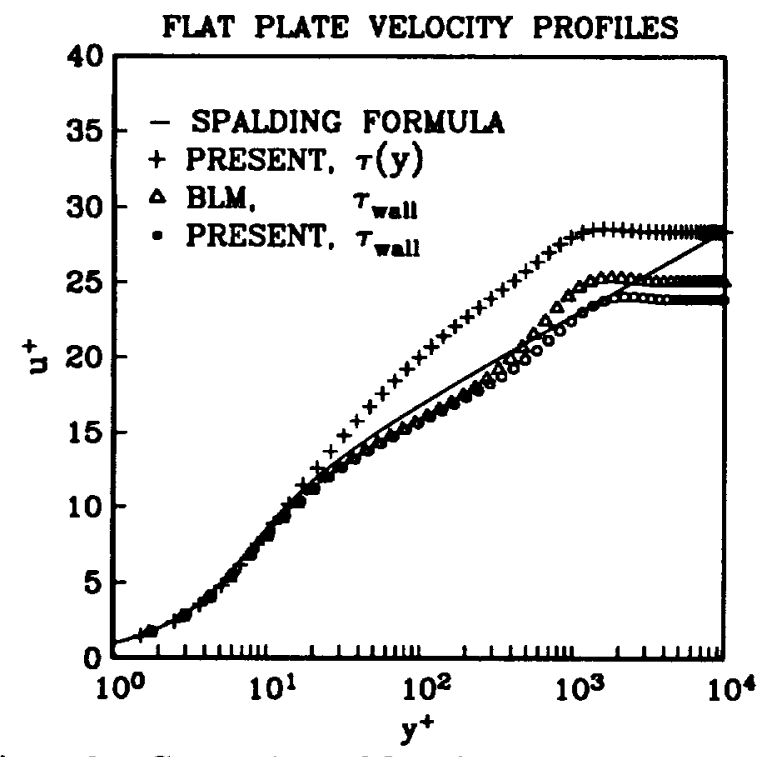

Figure 3.-Comparison of flat plate velocity profiles to Spalding's composite law of the wall.

the value $\bar{F}$ at $\bar{y}$, and a search through the array gives $\bar{y}(\bar{F})$.

The wake constant $C_{w k}$ is evaluated by equating the two options in (19) assuming a separating profile ( $\Pi=$ $\infty)$, giving:

$$
C_{w k}=\frac{F_{s e p}}{\bar{y}_{s e p} \Delta V}
$$

Substituting $F_{\text {sep }}=u_{e} \delta / 2, \bar{y}_{\text {sep }}=.606 \delta$, and $\Delta V / u_{e} \approx$ 1 (valid for separation or in the near wake) gives $C_{w k}=$ 0.825 .

In this work $\Delta V$ was taken to be $\left|V_{\max }\right|-\left|V_{\min }\right|$, as implied in the original BLM. It may be better to use $\Delta V=|V(\bar{y})|-\left|V_{\min }\right|$, as in recent work with the BLM.

Finally, the inner and outer turbulent viscosities are combined using Granville's blending function [12]:

$$
\mu_{e \jmath}=\mu_{o} \tanh \frac{\mu_{i}}{\mu_{o}}
$$

\section{3-D IMPLEMENTATION}

The turbulence model is applied in the blade-toblade $(\eta)$ and spanwise $(\zeta)$ directions independently. The length scale $y$ is computed differently in the inner and outer layers. For the inner layer the Buleev length scale based on the distance from the hub and blade is used to model near-wall effects.

$$
y_{i}=\frac{2 s_{\eta} s_{\zeta}}{s_{\eta}+s_{\zeta}+\sqrt{s_{\eta}^{2}+s_{\zeta}^{2}}}
$$

Using the local shear modification, the inner layer becomes independent of profile direction.

For the outer layer the actual distance from the appropriate wall is used to model boundary layer thickness effects, i.e., $y_{o}=s_{\eta}$ or $s_{\zeta}$. The outer layer gives

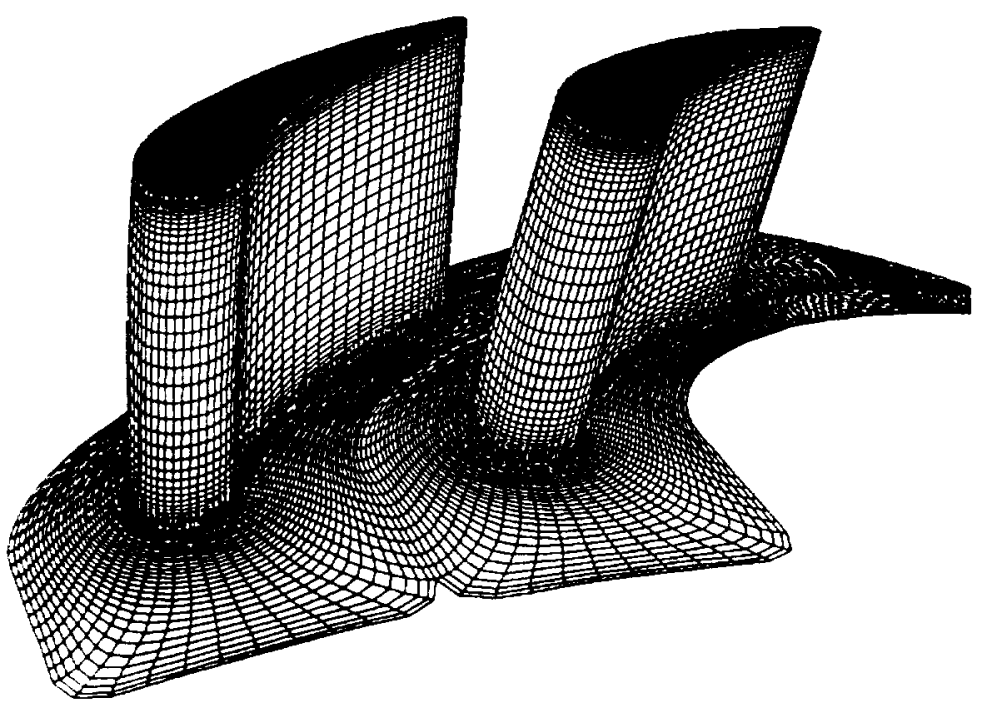

Figure 4.-Computational grid for the annular turbine cascade.

different profiles of $\mu_{t u r b}$ in the $\eta$ and $\zeta$ directions. The two profiles are combined vectorally:

$$
\mu_{t u r b}=\sqrt{\mu_{t \eta}^{2}+\mu_{t \zeta}^{2}}
$$

Although there is no physical argument for this combination, it has the appropriate behavior at both the wall and the free stream.

\section{RESULTS}

Calculations were made of a two-dimensional flat plate boundary layer at $M_{\infty}=0.25$. The grid had 248 points on the plate and 95 points normal to the plate, with the second grid point at $y^{+}<1$. Figure 3 shows three velocity profiles at $\operatorname{Re}_{x}=1.5 \times 10^{6}$ compared to Spalding's composite expression for the law of the wall. Profiles computed with both the BLM and the present model using $u^{*}=\sqrt{\tau_{\text {wall }} / \rho}$ agree well with Spalding's expression. However the profile computed with the present model using the local shear modification $u^{*}=\sqrt{\tau(y) / \rho}$ does not agree with the law of the wall. Apparently this disagreement has not been noticed before. It is recommended that the local shear modification be used with caution.

An annular cascade of turbine vanes tested experimentally at NASA Lewis Research Center by Goldman and McLallin [13] was analyzed. The computational grid had $127 \times 445 \times 63=360,045$ points and is shown in figure 4 . The solution converged 3.5 decades in 1,800 iterations, which took about 2.4 hours on a Cray Y-MP.

The vane has a constant cross section but the distance between vanes increases with radius, thereby increasing the vane loading. This is seen in the surface pressure distributions shown in figure 5 . The computed pressures agree very well with the experimental data. The spanwise variation of mixed out total pressure loss 


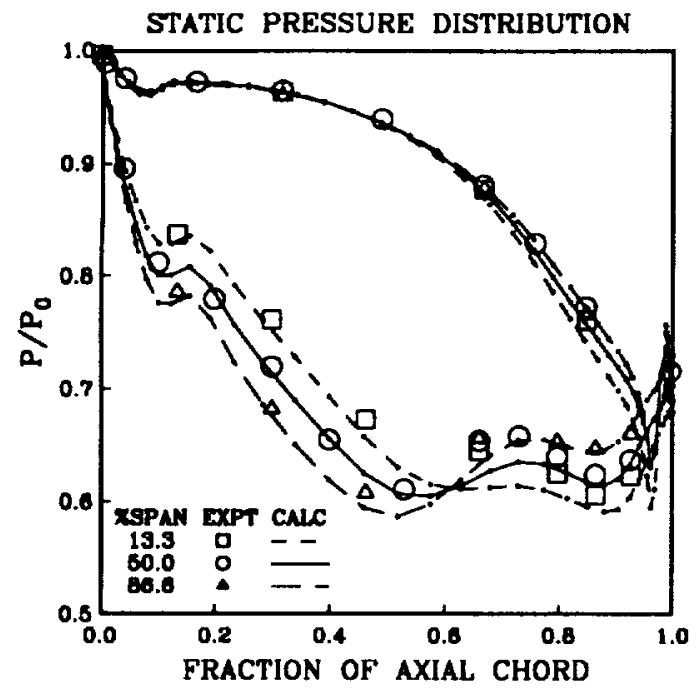

Figure 5.-Computed and measured pressure distributions for the annular turbine cascade.

coefficient downstream of the vanes is shown in figure 6 . The calculated losses are slightly higher than the measured losses. Figure 7 compares calculated and measured efficiency contours across the wake at a distance of $1 / 3$ axial chord downstream of the trailing edge. The kinetic energy efficiency is defined by:

$$
\eta=\frac{Q^{2}}{2 C_{p}\left(T_{0}-T\right)}
$$

where $Q$ is the total velocity, $T_{0}$ is the inlet total temperature, and $T$ is the static temperature. The overall measured efficiency was 0.96 and the computed efficiency was 0.94 . The shape of the computed wake is very similar to the measured wake, showing underturned, high loss regions near the endwalls due to secondary flows. However the computed wake has not mixed out as much as the measured wake, suggesting that the wake turbulence model may need improvement.

Calculations have also been made of endwall heat transfer in a linear turbine cascade. The cascade was tested experimentally by Boyle and Russell [7] over a wide range of chord Reynolds numbers $\mathrm{Re}_{c}$ and inlet boundary layer thicknesses $\delta_{i n}$. Endwall heat transfer was determined by appling electrical power to a foil heater covered by a liquid crystal sheet. The temperature at which the liquid crystal sheet exhibited a specific color was known from a calibration test. Colored bands on the sheet indicated isotherms, and since the heat flux was uniform they were also lines of constant heat transfer. By photographing the isotherms at several power settings the endwall Stanton number pattern was mapped. The Stanton number is defined by:

$$
\mathrm{St}=\frac{-\left(k \frac{\partial T}{\partial n}\right)_{\text {wall }}}{(\rho V)_{\text {in }} C_{p}\left(T_{\text {wall }}-T_{0 \text { in }}\right)}
$$

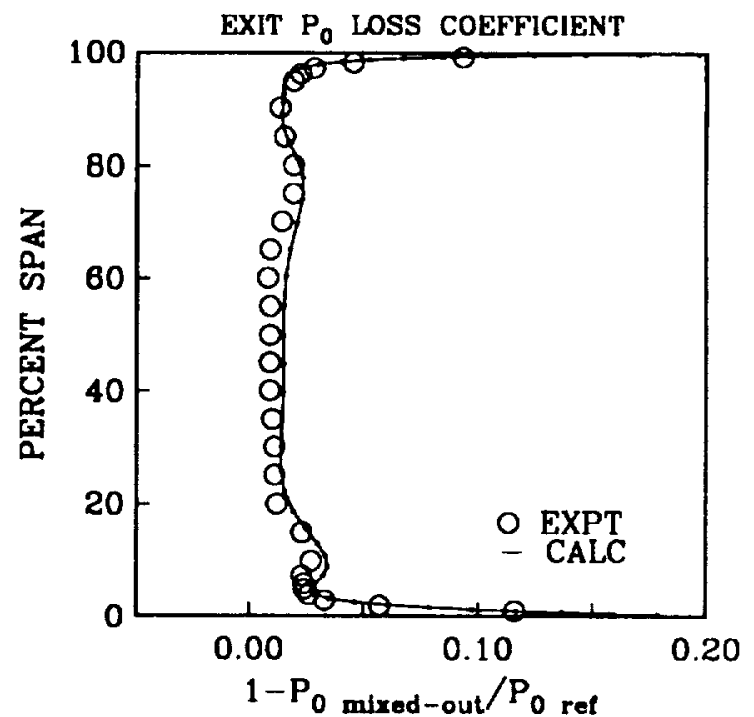

Figure 6.-Computed and measured loss coefficient profiles for the annular turbine cascade.

It was found that St increased somewhat as $\delta_{\text {in }}$ intcreased, with little change in the overall contour pattern. However, two distinct St contour patterns were seen at low and high $\mathrm{Re}_{c}$, as discussed below.

Two heat transfer cases were computed using the new turbulence model. The cases had similar inlet boundary layer thicknesses but very different $R_{c}$. The local shear modification to the van Driest damping (16) was used for both cases before the disagreement with the law of the wall was noted. The effects of this modification are discussed at the end of this section. The computational grid used for both cases is shown in figure 8. It has $165 \times 44 \times 41=297,660$ points on the half span. The second grid point was at $y^{+}<0.7$ for the low $\operatorname{Re}_{c}$ case and at $y^{+}<3.5$ for the high $\operatorname{Re}_{c}$ case.

The first case had $\operatorname{Re}_{c}=78,000, \delta_{i n}=.2 \times$ span, and $M_{i n} \approx 0.03$. To improve the convergence rate of the code, $M_{\text {in }}$ was scaled to 0.095 while maintaining $R_{e}$. The code took 4,000 iterations to converge three decades. Total CPU time on a Cray Y-MP was 4.4 hours. Figure 9 compares measured and computed endwall St contours for the low $\mathrm{Re}_{c}$ case. 'The experimental St contours (right) increase through the passage as the flow accelerates. The contours run from the leading edge region of the upper blade along the pressure surface, then deflect gradually towards the suction surface, resembling secondary flow streamlines near the endwall. The computed St contours (left) are about 20 percent low at the inlet but show fairly good agreement with the measured patterns in the front of the passage. The computed contours do not follow the pressure surface as closely as the measured contours, but the peak St in the throat region agrees reasonably well with the data.

The second case had $\operatorname{Re}_{c}=490,000, \delta_{\text {in }}=.15 \times$ span, and $M_{\text {in }}=0.175$. The code converged about 3.5 


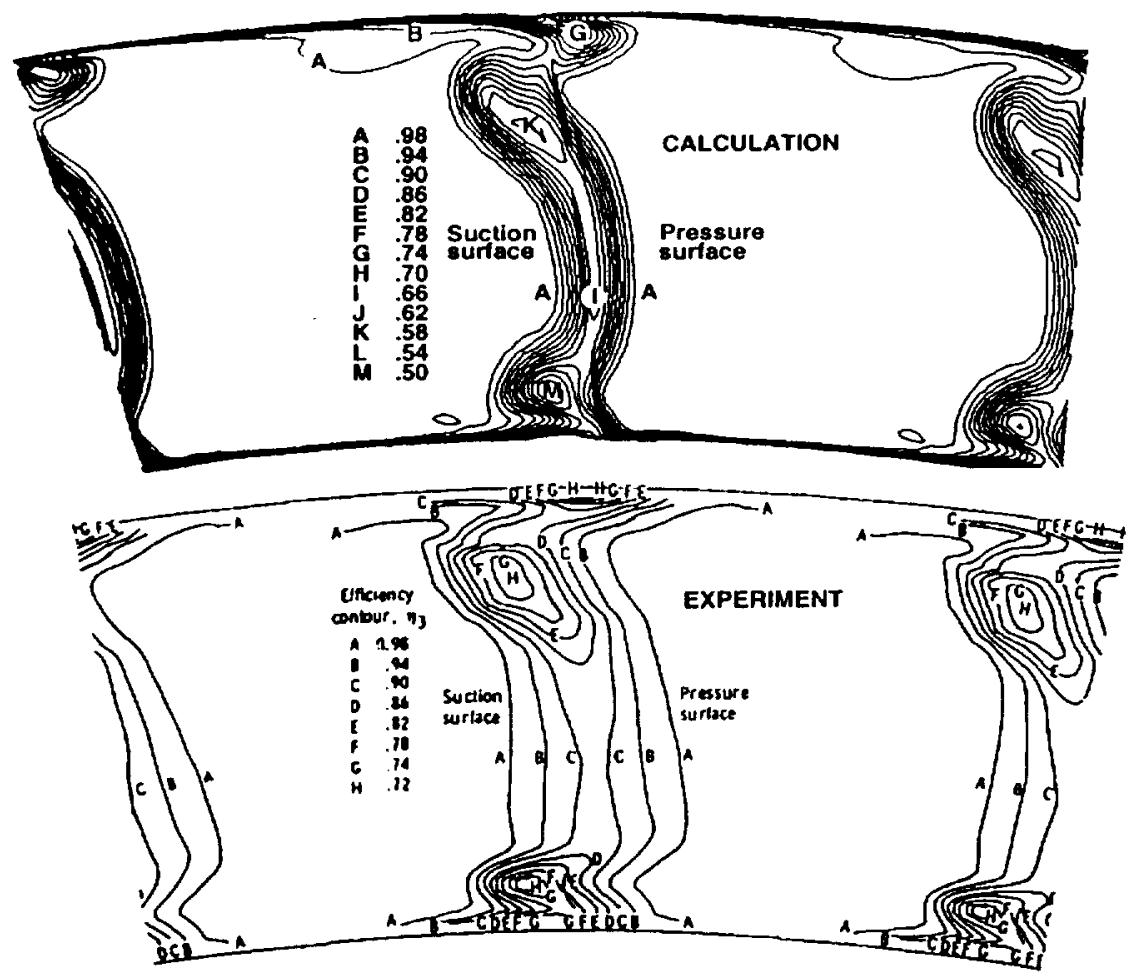

Figure 7.-Computed and measured contours of kinetic energy efficiency in the wake of the annular turbine cascade. turbine cascade.

orders of magnitude in $2.8 \mathrm{CPU}$ hours. Figure $10 \mathrm{com}$ pares measured and computed endwall St contours for the high $\mathrm{Re}_{c}$ case. Experimental St contours (right) are lower than the values seen at low $\operatorname{Re}_{c}$ and follow a different pattern. Here the experimental contours run almost directly from blade to blade, and the computed contours (left) agree closely. Endwall heat transfer augmentation near the blade leading edge is well predicted.

The two cases were analyzed to determine the physics behind the different St contour patterns. It was found that the differences are probably not due to differences in either the presure field or in secondary flow patterns, which are very similar for the two cases. The endwall Stanton numbers were quite sensitive to modifications to the van Driest damping. With a constant value of $A^{+}=26$ the Stanton numbers were high but did show some differences between the St patterns at different $\mathrm{Re}_{c}$. The local shear modification (16) reduced Stanton numbers by about 25 percent everywhere for both cases, giving better quantitative agreement with the experimental data. Both the local shear modification (16) and Cebeci's modification (18) accentuated the slope of the contours towards the front of the passage in the low $R_{e}$ case but had little effect at high $\mathbf{R e}_{c}$. The differences in the Stanton number patterns are thus consistent with relaminarization of the near-wall flow at low Reynolds numbers. It is hoped that further modifications to the van Driest damping formulation will better model the effects of favorable pressure gradients while remaining consistent with the law of the wall.

\section{SUMMARY}

A three-dimensional Navier-Stokes code was used to predict endwall heat transfer in a turbine cascade. Initial calculations using the Baldwin-Lomax turbulence model showed erratic heat transfer patterns due to a spurious maximum in the Baldwin-Lomax function $f(y)$ in the viscous sublayer. An analysis of the model showed that the problem was most likely to occur at the low Reynolds numbers and favorable pressure gradients found in low speed turbine cascades.

A new turbulence model was developed that uses unambiguous integral relations to estimate $\delta^{*} u_{e}$ and $\delta$. The model includes modifications to the van Driest damping function to account for the effects of pressure gradient. A new wake model was also proposed. Model constants were determined by comparison with the Cebeci-Smith model. It should be simple to retrofit the new model into existing codes that use the BaldwinLomax model.

For a flat plate boundary layer calculation, both the Baldwin-Lomax model and the present model showed good agreement with Spalding's expression for the law of the wall. However a commonly-used modification to van Driest's damping function caused disagreement with the law of the wall.

Calculations of flow in an annular turbine cascade showed good agreement with experimental pressure distributions. Computed wakes looked similar to measured wakes but showed less mixing, suggesting that the wake model may need improvement.

Calculations were also made of endwall heat transfer 
in a linear turbine cascade at two Reynolds numbers. Comparisons with experimental data showed that the model predicts observed variations in endwall Stanton number patterns with Reynolds number reasonably well.

\section{REFERENCES}

[1] Baldwin, B. S., Lomax, H., "Thin-Layer Approximation and Algebraic Model for Separated Turbulent Flows," AIAA Paper 78-257, Jan. 1978.

[2] Cebeci, T., Smith, A. M. O., Analysis of Turbulent Boundary Layers, Academic Press, N.Y., 1974.

[3] Boyle, R. J., "Navier-Stokes Analysis of Turbine Blade Heat Transfer," ASME Paper 90-G'T-42, June 1990.

[4] Visbal, M., Knight, D., "Evaluation of the Baldwin-Lomax Turbulence Model for TwoDimensional Shock Wave Boundary Layer Interaction," AIAA Paper 83-1697, July 1983

[5] Stock, H. W., Haase, W., "The Determination of Turbulent Length Scales in Algebraic Turbulence Models for Attached and Slightly Separated Flows Using Navier-Stokes Methods," AIAA Paper 871302, June 1987.

[6] Danberg, J. E., Patel, N. R., "An Algebraic Turbulence Model for Flow Separation Caused by Forward and Backward Facing Steps," Ballistic Research Lab. Report BRL-MR-3791, 1989.
[7] Boyle, R. J., Russell, L. M., "Experimental Determination of Stator Endwall Heat Transfer," ASME J. Turbomachinery, Vol. 112, 1984, pp 159-167.

[8] Chima, R. V., Yokota, J. W., "Numerical Analysis of Three-Dimensional Viscous Internal Flows," AIAA J., Vol. 28, No. 5, May 1990, pp. 798-806.

[9] Chima, R. V., "Viscous Three-Dimensional Calculations of Transonic Fan Performance," in CFD Techniques for Propulsion Applications, AGARD Conference Proceedings No. CP-510, AGARD, Neuilly-Sur-Seine, France, Feb. 1992., pp 21-1 to 21-19.

[10] Johnson, D. A., "Nonequilibrium Algebraic Turbulence Modeling Considerations for Transonic Airfoils and Wings," AIAA Paper 92-0026, Jan., 1992.

[11] Kays, W. M., "Heat Transfer to the Transpired Turbulent Boundary Layer," Int. J. Heat Mass Transfer, Vol. 15, 1992, pp 1023-1044.

[12] Granville, P. S. "A Near-Wall Eddy Viscosity Formula for Turbulent Boundary Layers in Pressure Gradients Suitable for Momentum, Heat or Mass Transfer," ASME J. Fluids Engr., Vol. 112, June 1990, pp. 25-28.

[13] Goldman, L. J., McLallin, K. L., "ColdAir Annular-Cascade Investigation of Aerodynamic Performance of Core-Engine-Cooled Turbine Vanes. I: Solid-Vane Performance and Facility Description," NASA TM X-3224, 1975.

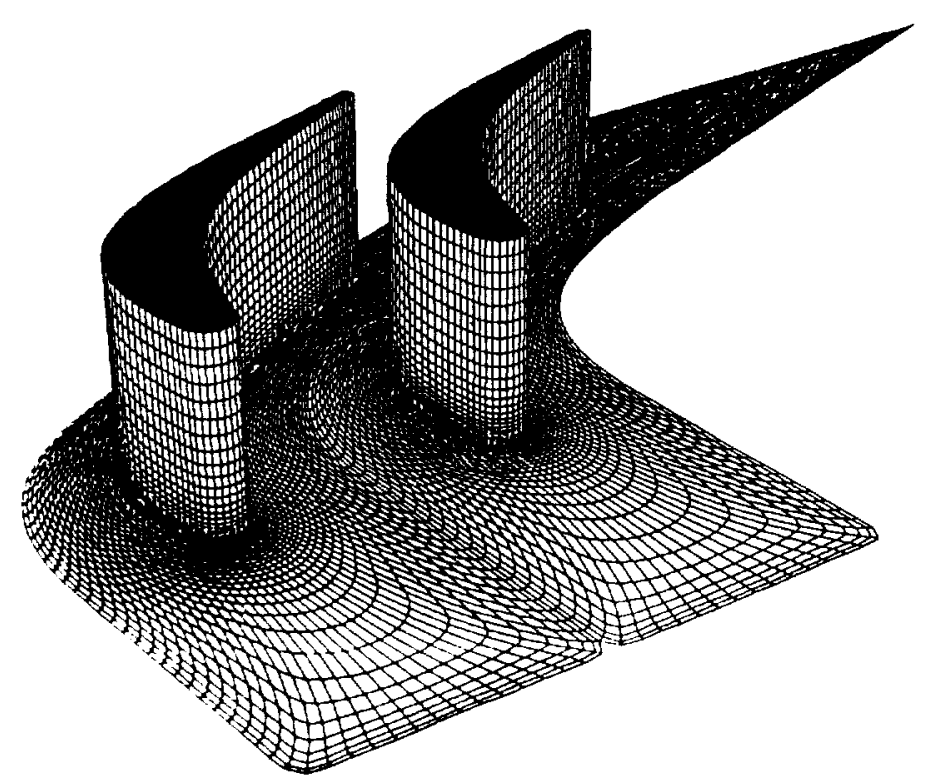

Figure 8.-Computational grid for the linear turbine cascade. 


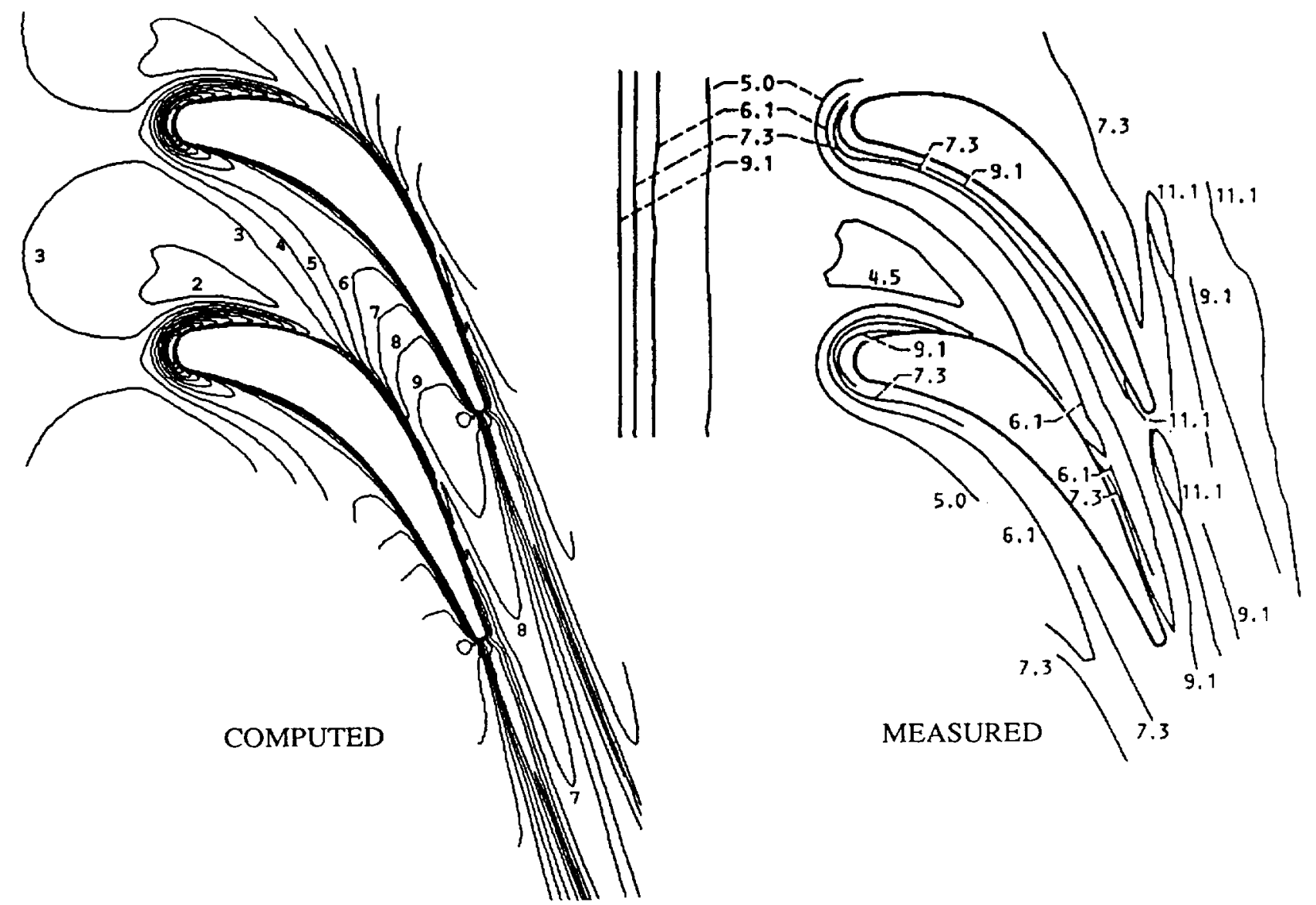

Figure 9.-Computed and measured contours of endwall Stanton number $\times 1000, \operatorname{Re}_{c}=78,000$.

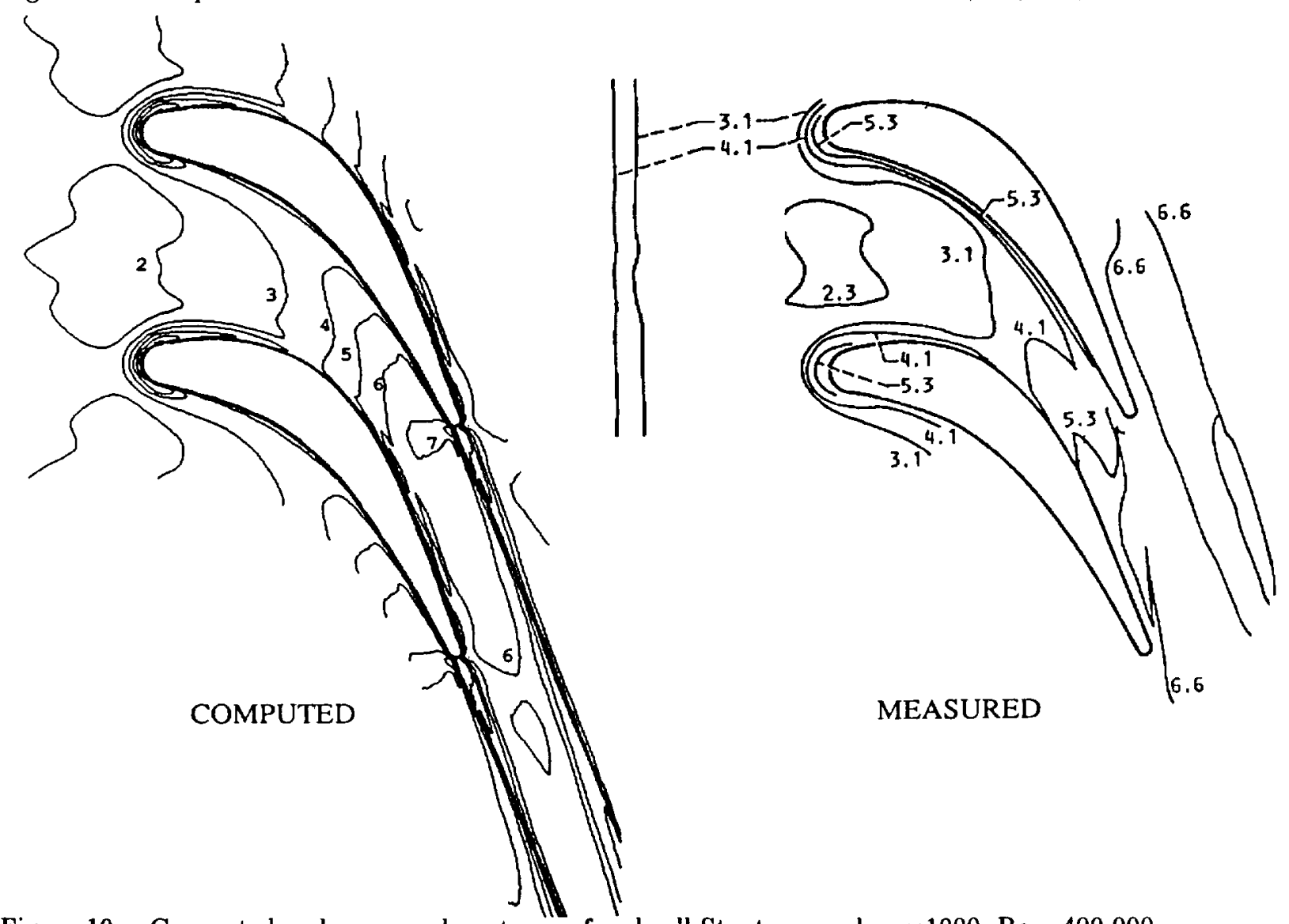

Figure 10.-Computed and measured contours of endwall Stanton number $\times 1000, \operatorname{Re}_{c}=490,000$. 
Public reporting burden for this collection of information is estimated to average 1 hour per response, including the time for reviewing instructions, searching existing data sources gathering and maintaining the data needed, and completing and reviewing the collection of intormation. Send comments regarding this burden estimate or any other aspect of this Headquarters Services. Directorate for intormat Davis Highway, Suite 1204, Arlington, VA 22202-4302, and to the Otfice of Management and Budget. Paperwork Reduction Project (0704-0188). Washington, DC 20503.

\begin{tabular}{|l|c|c|}
\hline 1. AGENCY USE ONLY (Leave blank) & $\begin{array}{c}\text { 2. REPORT DATE } \\
\text { January } 1993\end{array}$ & $\begin{array}{r}\text { 3. PEPORT TYPE AND DATES COVERED } \\
\text { Technical Memorandum }\end{array}$
\end{tabular}

4. TITLE AND SUBTITLE 5. FUNDING NUMBERS

An Algebraic Turbulence Model for Three-Dimensional Viscous Flows

6. AUTHOR(S)

WU $-535-(05-10$

R.V. Chima, P.W. Giel, and R.J. Boyle

7. PERFORMING ORgANIZATION NAME(S) AND ADDRESS(ES)

8. PERFORMING ORGANIZATION REPORT NUMBER

National Aeronautics and Space Administration

Lewis Research Center

Cleveland, Ohio 44135-3191

$E-7442$

9. SPONSORING/MONITORING AGENCY NAMES(S) AND ADDRESS(ES)

10. SPONSORING/MONITORING AGENCY REPORT NUMBER

National Aeronautics and Space Administration

Washington, D.C. 20546-0001

NASA TM- 10.5931

\section{SUPPLEMENTARY NOTES}

Prepared for the 3 lst Aerospace Sciences Meeting and Exhibit sponsored by the American Institute of Acronaulics and Astronisutics, Reno, Nevada, January 11-14, 1993. R.V. Chima and R.J. Boyle, NASA Lewis Research Center. P.W. Giel, Sverdrup Teclinology, Inc., I.ewis Research Center Group, Brook Park, Ohio 44142. Responsible person, R. V. Chima, (216) 433-5919.

12a. DISTRIBUTIONIAVAILABILITY STATEMENT

12b. DISTRIBUTION CODE

Unclassified - Unlimited

Subject Category 01

13. ABSTRACT (Maximum 200 words)

An algebraic turbulence model is proposed for use with three-dimensional Navier-Stokes analyses. It incorporates features of both the Baldwin-Lomax and Cebeci-Smith models. The Baldwin-Lomax model uses the maximum of at function $f(y)$ to determine length and velocity scales. An analysis of the Baldwin-Lomax model shows that $f(y)$ can have a spurious maximum close to the wall, causing numerical problems and non-physical results. The proposed model uses integral relations to determine $\delta^{*} u_{e}$ and $\delta$ used in the Cebeci-Smith model. It eliminates a constant in the Baldwin-Lomax model and determines the two remaining constants by comparison to the Cebeci-Smith formulation. Pressure gradient effects, a new wake model, and the implementation of these features in a three-dimensional Navier-Stokes code are also described. Result are shown for a flat plate boundary layer, an annular turbine cascade, and endwall heat transfer in a linear turbine cascade. The heat transfer results agree well with experimental data which shows large variations in endwall Stanton number contours with Reynolds number.

14. SUBJECT TERMS

Turbulence modelling; Baldwin-Lomax model; Cebeci-Smith model; Numerical methods; Turbines; Turbomachinery; Heat transfer

17. SECURITY CLASSIFICATION
OF REPORT
Unclassified

Unclassified

18. SECURITY CLASSIFICATION
OF THIS PAGE
Unclassified

19. SECURITY CLASSIFICATION OF ABSTRACT

Unclassified 